\title{
LA TOMA DE POSESION DEL OBJETO CON ANTERIORIDAD A LA FIRMEZA DEL ACUERDO DEL JURADO PROVINCIAL DE EXPROPIACION
}

351.712 .5

por

\section{Enrique Barrero González}

Jefe de Sección del Ayuntamiento de Sevilla

SUMARIO: I. INTRODUCCION.-II. LO QUE DISPONE LA LEY DE EXPROPIACION.-III. EL REGLAMENTO DE ESTA LEY.-IV. CRITERIO DE LA DOCTRINA.-V. LA SENTENCIA DE 20 DE ABRIL DE 1959.-VI. LA TESIS DE LA EJECUTIVIDAD DE LA RESOLUCION DEL JURADO.-VII. CONCLUSION.

\section{INTRODUCCION}

La expropiación forzosa es una de las instituciones jurídicas que más problemas prácticos plantea en su aplicación casuística. Basta repasar los repertorios de Jurisprudencia para comprobar el extraordinario número de cuestiones conflictivas que se someten al enjuiciamiento y resolución de los Tribunales en esta materia. La doctrina también se ha ocupado, con profusión, de los temas expropiatorios.

Sin embargo, no hemos visto tratado, con amplitud, un tema de frecuente aplicación práctica; nos referimos a la cuestión que plantea la toma de posesión del bien expropiado una vez que el justiprecio ha sido fijado por el Jurado Provincial de Expropiación 
Forzosa, pero el acuerdo de dicho Organismo no ha alcanzado la condición de firme, por haber sido impugnado ante la Jurisdicción contenciosa.

El tema se plantea en torno a si la Administración puede tomar posesión del objeto que expropia con la mera consignación del precio señalado por el Jurado o ha de esperar necesariamente a que el precio haya sido fijado de una manera definitiva e inapelable por el Tribunal correspondiente, o consignar, en caso contrario, no el precio fijado por el Jurado, sino la suma que el particular solicita en el recurso jurisdiccional. Por supuesto, se habla del caso de que no haya acuerdo entre la Administración y el expropiado, puesto que de existir dicho acuerdo los problemas se habrían obviado por la simple facultad dispositiva que los particulares poseen sobre su propio patrimonio.

Las presentes líneas se dedican a reflexionar sobre el tema mencionado, apuntando las razones que avalan una y otra postura, con la pretensión de que constituyan una llamada de atención para la clarificación legal del mismo o para la adopción por la Jurisprudencia de una postura unívoca y definida.

\section{LO QUE DISPONE LA LEY DE EXPROPIACION}

La Ley de Expropiación forzosa vigente no resuelve claramente la cuestión. El artículo 51 dispone que «hecho efectivo el justo precio, o consignado en la forma prevista en el artículo anterior, podrá ocuparse la finca por vía administrativa». En el supuesto de que el precio se hubiera hecho efectivo con la aquiescencia del expropiado, ningún problema se plantea, como antes dijimos. La cuestión surge cuando ha sido necesaria la consignación a que se refiere el artículo 50, al cual debemos, por tanto, descender para examinar la cuestión.

El artículo 50 dispone, en su párrafo $1 .^{\circ}$, «que cuando el propietario rehusase recibir el precio o cuando existiere cualquier litigio o cuestión entre el interesado y la Administración, se consignará el justiprecio por la cantidad que sea objeto de discordia en la Caja General de Depósitos, a disposición de la autoridad o Tribunal competente». Tenemos, por tanto, que, cumplido este requisito, puede ocuparse la finca.

Una primera interpretación literal del precepto transcrito se 
nos aparece como favorable a la tesis que interesa al particular, o sea, la de que no puede tomarse posesión del objeto expropiado hasta que no se consigne no la suma que ha fijado el Jurado, sino aquella que pretende el recurrente en su recurso jurisdiccional. Esta suma, y no otra, es aquella que es objeto de discordia, puesto que la que fija el Jurado resulta, en principio, vinculante para la Administración (1).

Sin embargo, la cuestión no aparece tan clara si se hace entrar en juego un método de interpretación jurídica más acorde con la indagación de la voluntad del legislador, sin detenerse en una mera interpretación gramatical, porque en todo caso lo dispuesto en el artículo 50 debe armonizarse con lo establecido en el artículo 48 de la propia Ley, que inicia el capítulo IV del título II referido al pago y toma de posesión.

Según este artículo, se procederá al pago de la cantidad «una vez determinado el justiprecio". Pero parece claro que la determinación del justiprecio a que alude la Ley no es la que en última instancia hagan los Tribunales jurisdiccionales, sino la que haga el Jurado en vía administrativa, puesto que el artículo 34 afirma que el Jurado decidirá ejecutoriamente, lo que equivale a señalar, siguiendo el criterio general aplicable a todos los actos administrativos, que su ejecución no puede quedar suspendida por la mera interposición de los recursos que la Ley autoriza.

\section{EL REGLAMENTO DE ESTA LEY}

Las dudas que en esta materia ofrece la aplicación de la Ley no fueron resueltas adecuadamente por el Reglamento. Antes, al contrario, puede deducirse que enturbió más la cuestión. En efecto:

Por de pronto, el artículo 48 del Reglamento contiene una distinción no prevista en la Ley según la expropiación se realice por la Administración territorial clásica (Estado, Provincia o Municipio) o por la Administración institucional. En el primer supuesto, el Reglamento alude expresamente a la determinación del justo precio por cualquiera de los procedimientos previstos en la Ley,

(1) En este sentido cabe advertir el distinto trato que mercce la Administración central y la local. Mientras un Ayuntamiento puede impugnar el acucrdo del Jurado $\sin$ otro requisito que el de la presentación del recurso, la Administración central debe acudir a una previa declaración de lesividad. (Sentencia de 7 de noviembre de 1969. Aranzadi 4950, entre otras). 
dejando abierta, mediante dicho pago, la posibilidad de la subsiguiente ocupación. En cambio, al tratar de los Organismos autónomos oficiales y expropiaciones realizadas en beneficio de particulares o empresas, establece expresamente que la Administración expropiante señalará el lugar y fecha de realización del pago una vez firme el precio de la expropiación, lo que induce a interpretar claramente a sensu contrario que no es necesaria dicha firmeza en el supuesto previsto en el párrafo 1, referido a la Administración del Estado, Provincia o Municipio.

Sin embargo, el propio Reglamento vuelve a incidir en confusiones, puesto que en el artículo 52 supedita la ocupación a la percepción de la indemnización o consignación en los términos previstos en el artículo 51, y este último artículo no ofrece la suficiente claridad ni saca abiertamente la conclusión que parece desprenderse de la interpretación que hemos señalado para el artículo 48 .

El artículo 51 enumera los casos en los que resulta procedente la consignación, señalando que debe efectuarse, entre otros casos, "cuando fueren varios los interesados y no se pusieren de acuerdo sobre la cantidad que a cada uno corresponde o existiere cualquier cuestión o litigio entre ellos, o entre ellos y la Administración». El párrafo 2 del mismo artículo (2) se encarga de precisar que «será objeto de consignación la cantidad a que asciende el justo precio o la parte del mismo objeto de discordia, según los casos, más la cantidad que proceda por el interés legal liquidado conforme a los artículos 56 y 57 de la Ley».

Una interpretación racional de dicho precepto no puede conducir a la consideración pura y simple de que la cantidad que debe depositarse, en el supuesto de recurso jurisdiccional del expropiado, es la que el propio recurrente solicita ante la Jurisdicción contenciosa, por la sencilla razón de que las cantidades que los expropiados solicitan suelen ser exhorbitadas y sería absurdo que se obligara a la Administración a la consignación de tan elevadas cantidades, dejadas en todo al arbitrio subjetivo del expropiado; máxime cuando la consignación debe hacerse «a disposición del expropiado" (artículo 51 , párrafo $3 .^{\circ}$ ), lo que no tendría sentido más que si se entiende que lo que se pone a su disposición es algo que ya tiene derecho a cobrar, según el criterio ejecutorio de la Administración, pero no lo que caprichosamente solicite ante la Jurisdicción com-

(2) Redactado nuevamente por Decreto $1.780 / 67$, de 13 de julio (Aranzadi 1471). 
petente (3). La discordia, pues, hay que entenderla referida bien a la diferencia que existe entre lo ofrecido por la Administración y lo señalado por el Jurado (en el supuesto de que la Administración no haya aceptado dicho precio), o bien, dentro de la cantidad fijada por el Jurado, a aspectos adjetivos del cobro, previstos en el propio párrafo $b$ ) del artículo 51 .

En todo caso, para completar esta visión panorámica de lo dispuesto en el Reglamento, merece la pena insistir en que el artículo 48 comienza aludiendo a la determinación del justo precio por cualquiera de los procedimientos previstos en el capítulo III del título II de la Ley, lo que refuerza la idea de que está teniendo presente la fijación administrativa del valor del objeto expropiado, de acuerdo con el carácter ejecutorio que atribuye a tal fijación en el artículo 39.

\section{CRITERIO DE LA DOCTRINA}

La doctrina en general se ha mantenido a favor de la tesis de la ejecutividad. RODRf́GUEz MORo (4) se pronuncia abiertamente por la tesis de la ejecutividad de los acuerdos del Jurado. Así nos dice, después de insistir en la regla general de la ejecutividad de los actos administrativos, que «la resolución del Jurado Provincial de Expropiación se presume justa. Y satisfecha esta cantidad o consignada en forma legal cuando el expropiado no quiera hacerse cargo de la misma, la Administración podrá ocupar el inmueble cuya utilidad o interés social y cuya necesidad de ocupación fueron anteriormente declaradas, pudiendo de ese modo llenar los cometidos de carácter público que con la expropiación se trataba de conseguir. Si a consecuencia de la reclamación el Tribunal modificó el precio, ninguna dificultad hay en cumplir y ejecutar su sentencia, no sufriendo con ello perjuicio alguno el expropiado». Más adelante añade que la vigente Ley ha sido en esto cuidadosa $\mathrm{y}$, si bien ha ofrecido garantía al expropiado, ha querido que la Admi-

(3) Para que se compruebe hasta qué punto el tema que nos ocupa está confusamente regulado, puede tomarse nota de la palpable discordancia que existe en este punto de la consignación entre la Ley y el Reglamento. Mientras éste, como hemos visto, señala la consignación a disposición del expropiado, la Ley (art. 50.1) la señala a disposición de la autoridad o Tribunal competente. Las consecuencias interpretativas que pueden obtenerse son radicalmente distintas.

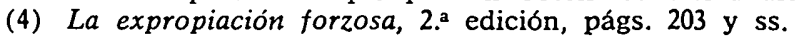


nistración no encuentre entorpecimiento sin justificación en el cumplimiento de sus cometidos de interés general.

Pera Verdaguer (5) mantiene en cierto modo un criterio contradictorio, pues en tanto afirma que «mientras la resolución no sea firme, el justo precio no ha sido realmente determinado, y, en consecuencia, mientras penda la posibilidad de interposición de un recurso no habrá llegado el momento de la procedencia del pago del precio", reconoce, a continuación, que la interposición del recurso no suspende la ejecución del acto impugnado, salvo la facultad de suspensión, de oficio a instancia de parte, que posee la autoridad ejecutante.

\section{LA SENTENCIA DE 20 DE ABRIL DE 1959}

Las posturas que sostienen la necesidad de esperar a la fijación definitiva del justiprecio en vía jurisdiccional, cuentan con el apoyo no sólo de la interpretación literal que antes aludíamos, sino de lo resuelto en la sentencia del Tribunal Supremo de 20 de abril de 1959, única que conocemos que se haya enfrentado abiertamente con el tema (6).

La expresada sentencia contempla el supuesto de una resolución del Jurado Provincial de Expropiación Forzosa recurrida por el interesado. La Alcaldía del Ayuntamiento expropiante comunicó a la propiedad que se le abonaría la cantidad señalada por el Jurado, que tendría carácter de entrega provisional por el litigio pendiente. Efectuado el depósito, el Ayuntamiento toma posesión del objeto expropiado, y la Sala de lo Contencioso de la Audiencia Territorial dicta sentencia aumentando el justiprecio y obligando al expropiante a entregar una suma adicional con el consiguiènte interés legal.

Formalizado recurso de apelación contra la sentencia indicada, el Tribunal Supremo lo estima, sin entrar a conocer el fondo del asunto, y declara la nulidad de la entrega del precio señalado por el Jurado y de los actos referentes al desalojo y ocupación de la finca. Todo ello con la particularidad de que el Tribunal actúa de

(5) Expropiación forzosa, Colección Nereo, pág. 234.

(6) Aranzadi 1718. La búsqueda de jurisprudencia sobre expropiación forzosa es extremadamente farragosa, dado el extraordinario número de sentencias existentes y la imposibilidad práctica de hacer una adecuada sistematización. 
oficio en su específica función revisora, velando por la pureza del procedimiento, afirmando que la apertura y desarrollo de cada período de la expropiación, momento de pago, plazo para el desalojo, ocupación de la finca y consignación de justiprecio es una cuestión de orden público, lo que conduce a declarar la ineficacia absoluta de las actuaciones infractoras.

La cuestión de fondo la resuelve la sentencia considerando que el acuerdo del Jurado no es firme, por haberse interpuesto contra él recurso contencioso-administrativo, razón por la cual no está determinado el justiprecio, y consiguientemente - dice la sentencia- son inoperantes e inaplicables hasta entonces las prescripciones de los artículos 48, 50 y 51 de la Ley de Expropiación, habiendo sido prematuros los actos municipales de oferta, entrega de precio y ocupación del predio expropiado, según los preceptos reguladores de la institución de Expropiación forzosa y de los términos empleados, por los artículos invocados, de justo precio, que es la cantidad que en firme fija el Jurado, si no se recurre en vía contenciosa contra su señalamiento, o la determinada por esta jurisdicción si fue recurrida, pero no el valor, precio en que cada parte estima la cosa expropiada.

\section{LA TESIS DE LA EJECUTIVIDAD DE LA RESOLUCION DEL JURADO}

Planteada de esta forma la cuestión, sólo nos resta efectuar un breve comentario para insistir, pese a esta sentencia (7), en la tesis de la posibilidad de ocupación del bien que se expropia con el solo pago -o consignación - de la cantidad fijada por el Jurado, sin perjuicio de los recursos procedentes.

Por de pronto, debe tomarse nota de que la sentencia transcrita es tan radical que va más allá incluso de los términos literales de la Ley, ya que al tachar los actos de consignación y ocupación de prematuros, parece estar preconizando que en todo caso habrá que esperar a la firmeza de la resolución del Jurado, cuando es obvio que en último extremo, aun no admitiendo la tesis de la ejecutoriedad de tal acuerdo, bastaría con la consignación de la cantidad controvertida u objeto de discordia.

Sin embargo, lo correcto es mantener sin limitaciones la tesis

(7) Es sabido que una sola sentencia no produce doctrina legal. 
de la ejecutividad del acuerdo del Jurado, en el sentido de que el pago o consignación de lo fijado por tal órgano es suficiente para la toma de posesión del objeto que se expropia, y ello no sólo en virtud de la teoría general de la ejecutividad de los actos administrativos, unánimemente consagrada en todos los textos vigentes, sino en virtud de una interpretación jurídica de los preceptos efectuada de acuerdo con un criterio institucional.

En cuanto a la relevancia que la teoría general de la ejecutividad de los actos administrativos tiene en este aspecto, no hay necesidad de insistir de manera especial. La idea de que la formulación de recursos no obsta a la ejecución del acto administrativo, está tan consagrada en la legislación vigente, en preceptos cuya cita, por conocidos, resulta innecesaria, que incluso la Ley de lo Contencioso establece un remedio especial para el supuesto en que el particular desee obtener la suspensión del acto administrativo, siempre que su ejecución pudiera causarle un daño de imposible o difícil reparación.

En cuanto a la interpretación institucional de la cuestión (8), no parece que ofrezca duda de que favorece la tesis que mantenemos, a condición de que manejemos todo el contexto de la institución expropiatoria, ya que si bien es cierto que la expropiación es una institución clásica del Derecho administrativo liberal, imbuido por el concepto de propiedad que deriva de tal concepción, no es menos cierto que una concepción moderna de esta institución tiene que hacer recaer su acento en el aspecto del interés público a que sirve (9), y en este sentido parece bastante claro que el interés público demanda que la ejecución de un proyecto o la instalación de un servicio no pueda verse indefinidamente demorado por un recurso jurisdiccional que incluso puede ser utilizado como mera táctica dilatoria.

Por otra parte, si se tiene en cuenta el ordenamiento jurídico

(8) La interpretación institucional ha sido popularizada en nuestro Derecho administrativo por la recepción de la obra de Forstr off. Significa, como es sabido, comprender a la norma por la conexión inmanente de este sentido que es propia de la institución y el puesto que ocupa dentro del sistema de ordenamiento jurídico (Tratado de Derecho administrativo). En nuestro país, la tesis de ForsthofF ha influido decisivamente en GARcfa DE ENTERRÍ, posiblemente el menos positivista de nuestros autores administrativos.

(9) Téngase en cuenta, por ejemplo, la moderna inclusión del interés social al lado de la utilidad pública como causas legitimadoras de la expropiación, la ampliación del concepto expropiatorio a otros supuestos que los de la clásica enajenación plena o transmisiva de los bienes inmuebles, etc.; vid., al respecto, GARcfa DE ENTERRfa, Los principios de la nueva Ley de Expropiación forzosa. I. E. P., Madrid. 
global, como recomienda el criterio interpretativo institucional, no puede dejarse de tener en cuenta el radical giro que en la actualidad se ha producido en la concepción del dominio, consagrado en cuanto al Derecho positivo en la Ley del Suelo y Ordenación urbana, lo que conduce, sin mengua de las garantías jurídicas de los administrados, consagradas en cualquier estado de Derecho que se precie seriamente de serlo, a interpretaciones que están en radical discordancia (10) con el concepto liberal de la propiedad.

Nada más lógico, pues, que preconicemos aquí una interpretación de la Ley de Expropiación forzosa acorde con esta nueva concepción socializadora, más atenta al interés público y a sus exigencias que a aspectos puramente formales.

\section{CONCLUSION}

Podemos resumir lo expuesto con anterioridad, estableciendo las siguientes afirmaciones:

1. ${ }^{\text {a }}$ El tema de la posibilidad de ocupación de los bienes expropiados, mediante la consignación del precio fijado por el Jurado Provincial de Expropiación Forzosa, cuando el acuerdo de este órgano es objeto de recurso jurisdiccional y no existe conformidad del expropiado, no está resuelto con claridad ni en la Ley de Expropiación forzosa ni en su Reglamento de aplicación.

2. ${ }^{\text {a }} \quad$ La Jurisprudencia en alguna ocasión se ha pronunciado en contra de la tesis de la ejecutividad del acuerdo del Jurado y afirma que debe esperarse a la firmeza del acuerdo para poder proceder a la toma de posesión.

3. ${ }^{a}$ Una interpretación institucional del precepto, conjugada con la tesis de la ejecutividad general en todo acto administrativo, conduce a una interpretación favorable al interés público, en el sentido de que la consignación de precio fijado por el Jurado es suficiente para la toma de posesión del objeto expropiado.

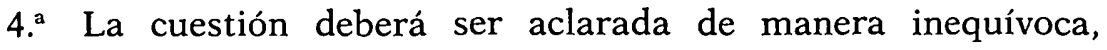
para evitar los confusionismos que en la práctica administrativa puedan producirse y que de hecho se producen.

(10) Recuérdese, por ejemplo, el importante tema de la cesión obligatoria y gratuita de viales, caracterizado en la Ley como una "carga connatural de la propiedad urbanan, aplicable a cualquier sistema de gestión urbanística (sentencia de 15 de febrero de 1966); las interpretaciones restrictivas de que ha sido objeto la recuperación de facultades dominicales a que alude el artículo 56 de la Ley del Suelo (sentencia de 30 de marzo de 1974, Aranzadi 1509), etc. 
REVL-1974, núm. 183. BARRERO GONZALEZ, ENRIQUE. LA TOMA DE POSESION DEL OBJETO C... REVL-1974, núm. 183. BARRERO GONZALEZ, ENRIQUE. LA TOMA DE POSESION DEL OBJETO C... 


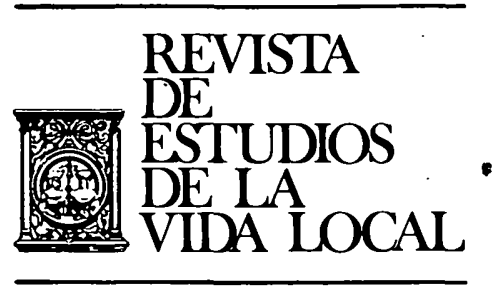

II. CRONICAS 
REVL-1974, núm. 183. BARRERO GONZALEZ, ENRIQUE. LA TOMA DE POSESION DEL OBJETO C... REVL-1974, núm. 183. BARRERO GONZALEZ, ENRIQUE. LA TOMA DE POSESION DEL OBJETO C... 